\section{Polycomb EZH2 controls self-renewal and safeguards the transcriptional identity of skeletal muscle stem cells}

\author{
Aster H. Juan, ${ }^{1}$ Assia Derfoul, ${ }^{1,4}$ Xuesong Feng, ${ }^{1,4}$ \\ James G. Ryall, ${ }^{1,4}$ Stefania Dell'Orso, ${ }^{1,4}$ \\ Alessandra Pasut, ${ }^{2,4}$ Hossein Zare, ${ }^{1}$ James M. Simone ${ }^{3}$ \\ Michael A. Rudnicki, ${ }^{2}$ and Vittorio Sartorelli, ${ }^{1,5}$ \\ ${ }^{1}$ Laboratory of Muscle Stem Cells and Gene Regulation, \\ National Institute of Arthritis, Musculoskeletal, and Skin \\ Diseases (NIAMS), National Institutes of Health, Bethesda, \\ Maryland 20892, USA; ${ }^{2}$ The Sprott Centre for Stem Cell \\ Research, Regenerative Medicine Program, Ottawa Hospital \\ Research Institute, Ottawa, Ontario K1H8L6, Canada; \\ ${ }^{3}$ Flow Cytometry Section, NIAMS, National Institutes of \\ Health, Bethesda, Maryland 20892, USA
}

Satellite cells (SCs) sustain muscle growth and empower adult skeletal muscle with vigorous regenerative abilities. Here, we report that EZH2, the enzymatic subunit of the Polycomb-repressive complex 2 (PRC2), is expressed in both $\mathrm{Pax}^{+} / \mathrm{Myf5}^{-}$stem cells and $\mathrm{Pax} 7^{+} / \mathrm{Myf}^{+}$committed myogenic precursors and is required for homeostasis of the adult SC pool. Mice with conditional ablation of Ezh2 in SCs have fewer muscle postnatal $\operatorname{Pax} 7^{+}$cells and reduced muscle mass and fail to appropriately regenerate. These defects are associated with impaired SC proliferation and derepression of genes expressed in nonmuscle cell lineages. Thus, EZH2 controls self-renewal and proliferation, and maintains an appropriate transcriptional program in SCs.

Supplemental material is available for this article.

Received January 1, 2011; revised version accepted March 3, 2011.

Adult skeletal muscle regenerates in response to traumatic injuries or degenerative conditions. This property is afforded mainly by satellite cells (SCs), a heterogeneous population of resident committed myogenic progenitors and noncommitted stem cells (Sherwood et al. 2004; Collins et al. 2005; Montarras et al. 2005; Kuang et al. 2007). In the mouse, postnatal SCs are mitotically active for the initial $2 \mathrm{wk}$ after birth. After this period, they enter quiescence and their number declines. However, following muscle injury or degeneration, adult SCs undergo intense proliferation and efficiently differentiate. To replenish the reservoir, a subset of dividing SCs returns to the niche following a process of asymmetric and

[Keywords: Polycomb; Ezh2; satellite cells; muscle growth; muscle regeneration]

${ }^{4}$ These authors contributed equally to this work.

${ }^{5}$ Corresponding author.

E-MAIL sartorev@mail.nih.gov; FAX (301) 480-9699.

Article is online at http://www.genesdev.org/cgi/doi/10.1101/gad.2027911. symmetric cell division (Shinin et al. 2006; Conboy et al. 2007; Kuang et al. 2007; Shea et al. 2010). Approximately $10 \%$ of noncommitted $\mathrm{Pax} 7^{+} / \mathrm{Myf}^{-}$SCs can asymmetrically generate a self-renewing, noncommitted $\mathrm{Pax} 7^{+} /$ Myf5 $5^{-}$cell and a committed $\mathrm{Pax} 7^{+} / \mathrm{Myf}^{+}$daughter cell in vivo. The noncommitted $\mathrm{Pax} 7^{+} / \mathrm{Myf} 5^{-}$cell returns to the niche to maintain the SC reservoir, while the committed $\mathrm{Pax} 7^{+} / \mathrm{Myf}^{+}$SC undergoes several rounds of cell division and the ensuing cells eventually differentiate into pre-existing or newly formed myofibers (Kuang et al. 2008).

Polycomb group (PcG) proteins regulate differentiation of totipotent embryonic stem (ES) cells and maintenance of multipotent and progenitor stem cell populations (Sauvageau and Sauvageau 2010). The Polycomb-repressive complex 2 (PRC2) subunit EZH2 methylates histone H3 Lys 27 (H3K27me3), establishing an epigenetic mark that identifies repressed chromatin regions. Ablation of PRC2 members in ES cells impairs their differentiation (Pasini et al. 2007; Chamberlain et al. 2008; Shen et al. 2008) and results in unscheduled expression of mixed cell lineage genes (Boyer et al. 2006; Lee et al. 2006). While PcG establishes and maintains positional patterning of the body axis through regulation of Hox genes in both Drosophila and mammals, its role in conferring cell identity by repressing inappropriate cell lineage-specific transcription in animal development has not been demonstrated. Indeed, derepression of mixed cell lineage genes does not occur in epidermal, neuronal, or pancreatic cells of Ezh2 conditional null mice (Chen et al. 2009; Ezhkova et al. 2009; Hirabayashi et al. 2009).

We generated mice in which Ezh2 was conditionally ablated in SCs (Ezh2 muscle knockout, Ezh2 $\left.{ }^{\mathrm{mKO}}\right)$. While EZH2 was dispensable for fetal muscle development, it was required for postnatal muscle growth and adult muscle regeneration, ensuring appropriate homeostasis of the SC pool. Unlike other progenitor cells, reduced H3K27me3 in Ezh2 ${ }^{\text {mKO }}$ SCs was accompanied by RNA polymerase II (PolII) recruitment and transcriptional activation of genes normally repressed in SCs and expressed in other cell lineages, including cardiac progenitors, retinal cones, neurons, and chondrocytes. Thus, our findings indicate that $\mathrm{EZH} 2$, which regulates proliferation and maintains transcriptional identity of adult muscle stem cells, is an important molecular component of adult skeletal myogenesis.

\section{Results and Discussion}

Pax7 and Ezh2 are coexpressed in postnatal SCs

Pax7 is essential for SC specification and survival (Buckingham and Relaix 2007). While $\mathrm{Pax} 7^{+}$cells were present at embryonic day 15.5 (E15.5) and E17.5, EZH2 could not be detected in skeletal muscle but was expressed in the epidermis (Supplemental Fig. S1A; Ezhkova et al. 2009). At postnatal day 1 (P1), EZH2 was expressed in limb muscles, where it remained detectable, along with $\operatorname{Pax} 7$, for $\sim 14 \mathrm{~d}$ (P14) (Fig. 1A). Indeed, the vast majority of Pax $7^{+}$ cells coexpressed EZH2 in muscle cross-sections of P8 animals (Fig. 1B). Both EZH2 and Pax7 decreased and became undetectable by immunoblot after P21 (Fig. 1A), consistent with cessation of myonuclei accretion. 
Juan et al.

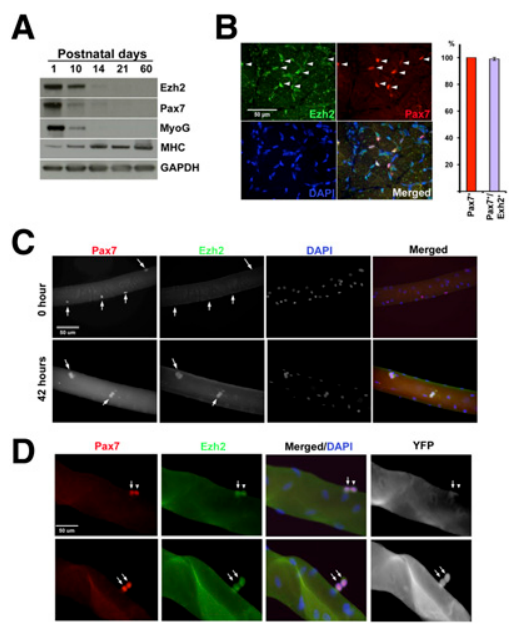

Figure 1. Ezh2 expression in limb muscles and SCs. $(A)$ Limb muscle extracts from mice at $\mathrm{P} 1-\mathrm{P} 60$ probed with the indicated antibodies. (B) In P8 hindlimb muscles, EZH2 is expressed in Pax $7^{+}$cells. Arrowheads indicate cells positive for Pax7 and EZH2. Quantification of $\mathrm{Pax}^{+} / \mathrm{EZH2}{ }^{+}$cells in P8 EDL muscles. $(C$, top panel) Myofiberassociated quiescent $(0 \mathrm{~h}) \mathrm{Pax}^{+} \mathrm{SCs}$ do not express a detectable level of EZH2. (Bottom panel) After $42 \mathrm{~h}, \mathrm{EZH} 2$ is expressed in couplets of dividing Pax $7^{+}$SCs. $(D)$ In single myofibers of Myf5-Cre/ROSA-YFP mice cultured for $42 \mathrm{~h}$, EZH2 is expressed in both $\mathrm{Pax}^{+} / \mathrm{YFP}^{-}$(top panel) and $\mathrm{Pax}^{+} / \mathrm{YFP}^{+}$(bottom panel) cells. Arrows indicate $\mathrm{YFP}^{+}$ cells, and arrowheads indicate $\mathrm{YFP}^{-}$cells. Bars, $50 \mu \mathrm{m}$.

\section{Ezh2 is expressed in both noncommitted and myogenically committed proliferating SCs}

To evaluate EZH2 expression in quiescent and activated (i.e., cells that have entered the cell cycle) SCs, individual myofibers and their associated SCs were isolated from the extensor digitorus longus (EDL) muscle of 2-mo-old mice (P60) and either fixed immediately or cultured for $42 \mathrm{~h}$ to stimulate SC proliferation. While Pax7 was expressed in both conditions, EZH2 was detected only in $\mathrm{Pax}^{+}$dividing SCs at $42 \mathrm{~h}$ (Fig. 1C). Neither Pax7 nor EZH2 was detected in myofiber nuclei (Fig. 1C). The low abundance of SCs at P21 prevented Pax7 detection (Fig. 1A).

The SC pool is composed of at least two hierarchical subpopulations (Kuang et al. 2007). Pax $7^{+} / \mathrm{Myf5}^{-}$cells are noncommitted self-renewing stem cells maintaining the $\mathrm{SC}$ compartment and giving rise to $\mathrm{Pax}^{+} / \mathrm{Myf}^{+}$myogenic committed precursors fated to differentiate into myofibers. To investigate EZH2 expression in these two subpopulations, we used a lineage-tracing approach based on the Myf5-Cre/ROSA-YFP mouse, where cells that express or have ever expressed Myf5-Cre are $\mathrm{YFP}^{+}$, while cells that have never expressed Myf5-Cre are $\mathrm{YFP}^{-}$(Kuang et al. 2007). Immunostaining with Pax7 and EZH2 antibodies of Myf5-Cre/ROSA-YFP myofibers cultured for $42 \mathrm{~h}$ in growth medium revealed that Pax7 and EZH2 were coexpressed in both $\mathrm{YFP}^{-}$(Fig. 1D, top panel) and $\mathrm{YFP}^{+}$ (Fig. 1D, bottom panel) cells (Fig. 1D). Thus, EZH2 is expressed in both dividing $\mathrm{Pax}^{+} / \mathrm{Myf5}^{-}$noncommitted stem cells and $\mathrm{Pax}^{+} / \mathrm{Myf}^{+}$muscle progenitors.

Mice with conditional ablation of Ezh2 in Pax7-derived muscle precursor cells have reduced muscle mass with smaller myofibers

Ezh2 was selectively ablated in Pax7-derived cells by crossing knock-in mice expressing Cre recombinase from the Pax7 locus (Pax7-Cre) (Keller et al. 2004) with mice bearing floxed Ezh2 alleles (Su et al. 2003). In Pax7-Cre ${ }^{+/-}$; Ezh2 ${ }^{\mathrm{fl} / \mathrm{fl}}$ mice $\left(E z h 2^{\mathrm{mKO}}\right)$, both EZH2 RNA and protein were largely and specifically reduced in muscle tissue (Fig. 2A). Ezh2 deletion did not affect the expression of other members of the PRC2 complex, Suz12 and Eed, or the PRC1 protein Bmil (Supplemental Fig. S2A). Ezh2 floxed alleles were not deleted in the kidney, heart, and white fat (data not shown). Ezh2 ${ }^{\mathrm{mKO}}$ mice had no obvious feeding difficulties and were apparently healthy. At E17.5, when EZH2 is not expressed in muscle tissues (Supplemental Fig. S1A), we did not observe gross morphological changes or appreciable abnormalities in Ezh2 ${ }^{\mathrm{mKO}}$ fetal myofibers (Supplemental Fig. S1B). In addition, a comparable number of $\mathrm{Pax}^{+}$cells in the EDL of $E z h 2^{\mathrm{mKO}}$ and littermate controls further suggested that EZH2 is not required for fetal muscle development (Supplemental Fig. S1B). However, at P8, the muscle size of Ezh2 ${ }^{\mathrm{mKO}}$ animals was obviously smaller than that of littermate controls, and myofibers with a reduced cross-sectional area (CSA) were prevalent (Supplemental Fig. S2B,C). The myofiber number was comparable with that of littermate controls. These postnatal muscle defects persisted through adulthood, and both the body mass and the total muscle mass of P60 Ezh2 ${ }^{\mathrm{mKO}}$ animals were significantly reduced (Fig. 2B,C), with a prevalence of smaller myofibers (Fig. 2D). Thus, Ezh2 ablation in Pax7-derived skeletal muscle cells results in defects of postnatal muscle growth characterized by reduced muscle mass with smaller muscle fibers.

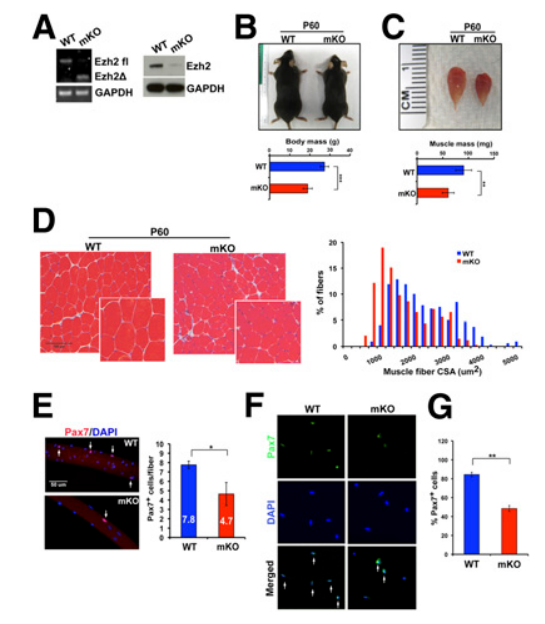

Figure 2. Conditional Ezh2 ablation results in postnatal skeletal muscle defects and an impoverished SC pool. (A) RNA (left) and protein (right) analysis of Ezh2 in wild-type (WT) (Pax7-Cre ${ }^{-1-}$; $\left.E z h 2^{\mathrm{fl} / \mathrm{fl}}\right)$ and $\mathrm{mKO}\left(\mathrm{Pax} 7-\mathrm{Cre}^{+/-} ; E z h 2^{\mathrm{fl} / \mathrm{fl}}\right)$ littermates. EZH2fl and EZH2 $\Delta$ correspond to floxed and SET-deleted Ezh2 RNAs, respectively. $(B, C)$ Both body and muscle mass are significantly reduced in P60 mKO compared with control (wild-type) littermates. Data are presented as mean $\left.\pm \mathrm{SD}(n=6) ;\left(^{\star \star \star}\right) P<0.0005 ;\left.\right|^{\star \star}\right) P<0.005 .(D)$ $\mathrm{H} \& \mathrm{E}$ staining of transverse sections of P60 TA reveals a reduced myofiber CSA in $E z h 2^{\mathrm{mKO}}$ animals $(n=3)$. Ninety-five percent confidence intervals do not overlap. (E) EDL single myofibers from adult (P60) Ezh2 $2^{\mathrm{mKO}}$ animals have a reduced number of SCs. Arrows indicate $\mathrm{Pax} 7^{+}$cells. Data are presented as mean $\pm \mathrm{SD}(n=6)_{;}\left(^{*}\right) P<$ 0.05. $(F, G)$ Pax7 immunostaining of FACS-isolated wild-type and Ezh $2^{\mathrm{mKO}}$ SCs. Arrows indicate cells stained positive for Pax7 and DAPI. Data are presented as mean $\pm \mathrm{SD}(n=3)_{;}\left(^{\star \star}\right) P<0.005$. 
Ezh2 is required for maintenance of the adult muscle SC pool

We examined the quiescent SC population of P60 mice. $\mathrm{Pax}^{+}$cells on freshly isolated individual myofibers were reduced by $\sim 40 \%$ in Ezh2 ${ }^{\mathrm{mKO}}$ animals (Fig. 2E). To further substantiate these findings, we isolated the quiescent SC population from both wild-type and Ezh2 $2^{\text {mKO }}$ animals by FACS by gating on integrin $\alpha-7^{+}$(positive selection) and $\mathrm{Lin}^{-}\left(\mathrm{CD} 31^{-}, \mathrm{CD} 45^{-}, \mathrm{CD} 11^{-}\right.$, Sca1 ${ }^{-}$) (negative selection) cells. Although the percentage of the integrin- $\alpha 7^{+} \operatorname{Lin}^{-}$population was similar in wild type and Ezh2 ${ }^{\text {mKO }}$ (Supplemental Fig. 3A), only $\sim 50 \%$ of the purified cells were $\mathrm{Pax}^{+}$in Ezh2 ${ }^{\mathrm{mKO}}$ compared with $\sim 85 \%$ in wild type (Fig. $2 \mathrm{~F}, \mathrm{G}$ ). In agreement with the results reported above, muscle cross-sections of Ezh2 ${ }^{\mathrm{mKO}}$ animals contained only $\sim 50 \%$ of the $\mathrm{Pax}^{+}$cells of littermate controls (Supplemental Fig. S3B). Reduced Pax7 expression in Ezh2 ${ }^{\mathrm{mKO}}$ is not the consequence of direct regulation by EZH2, since adenoviral Cre-mediated Ezh2 excision did not affect the Pax7 level (Supplemental Fig. S3C). Together, these data suggest that EZH2 regulates establishment and/or maintenance of the adult SC pool.

\section{Ezh2 affects SC proliferation and differentiation}

We evaluated the SC population by quantifying $\mathrm{Pax}^{+}$ cells in P8 mice, when SCs are highly proliferative. Pax $7^{+}$ cells, located under the basal lamina, were decreased by $\sim 40 \%$ in Ezh2 ${ }^{\mathrm{mKO}}$ animals and, consistent with Ezh2 ablation, H3K27me ${ }^{+}$cells were hardly detected (Fig. 3A,B; Supplemental Fig. S3D). The reduced number of $\mathrm{Pax}^{+}$cells in Ezh2 ${ }^{\mathrm{mKO}}$ animals suggested that SC proliferation may be impaired. To test this hypothesis, individual myofibers derived from either wild-type or Ezh2 ${ }^{\mathrm{mKO}}$ EDL muscle were isolated and cultured for $3 \mathrm{~d}$ to allow for SC delamination and proliferation. The number of $\mathrm{Pax}^{+}$cells derived from 3 -d cultured Ezh2 ${ }^{\mathrm{mKO}}$ myofibers was significantly curtailed, when compared with that of wild-type myofibers (Fig. 3C). An equivalent number of FACS-isolated cells obtained from either wildtype or Ezh2 $2^{\mathrm{mKO}}$ animals was plated and cultured for 14, 48, and 96 h, respectively. Fewer Ezh2 ${ }^{\text {mKO }}$ cells were present after 48 and $96 \mathrm{~h}$ in culture (Fig. 3D). 5-bromo-2'-deoxyuridine (BrdU) cell incorporation and immunostaining with an antibody detecting histone H3Ser10 phosphorylation-a marker of the G2/M mitotic transition-indicated that Ezh $2^{\mathrm{mKO}}$-derived cells had reduced proliferative capacity (Fig. 3E). Apoptosis was not increased in Ezh2 ${ }^{\mathrm{mKO}}$ SCs (Supplemental Fig. S4A). The proliferation defects of Ezh2 ${ }^{\mathrm{mKO}}$ SCs are likely the consequence of derepression of the cell cycle inhibitor p16 (Cdkn2a) (Fig. 3F; Supplemental Table S1; Bracken et al. 2007; Kotake et al. 2007; Chen et al. 2009; Ezhkova et al. 2009; Pereira et al. 2010). To directly test this hypothesis, we reduced p16 in FACS-isolated and cultured SCs by siRNA (Supplemental Fig. S4B). A higher percentage of Ezh2 ${ }^{\mathrm{mKO}}$ SCs with reduced p16 scored positive for H3Ser10 phosphorylation compared with control siRNA transfected Ezh2 ${ }^{\text {mKO }}$ SCs. Reducing p16 did not affect H3Ser10 phosphorylation of wild-type SCs. (Supplemental Fig. S4B). Thus, p16 up-regulation is partly responsible for the proliferative defects of Ezh2 $2^{\text {mKO }}$ SCs. Despite the reduced number of $\mathrm{Pax}^{+}$cells per clone (Fig. $3 \mathrm{Cl}$, the majority of Ezh2 ${ }^{\mathrm{mKO}}$ SCs cultured for $72 \mathrm{~h}$ expressed myogenin (Fig. 3G), suggesting earlier differen-
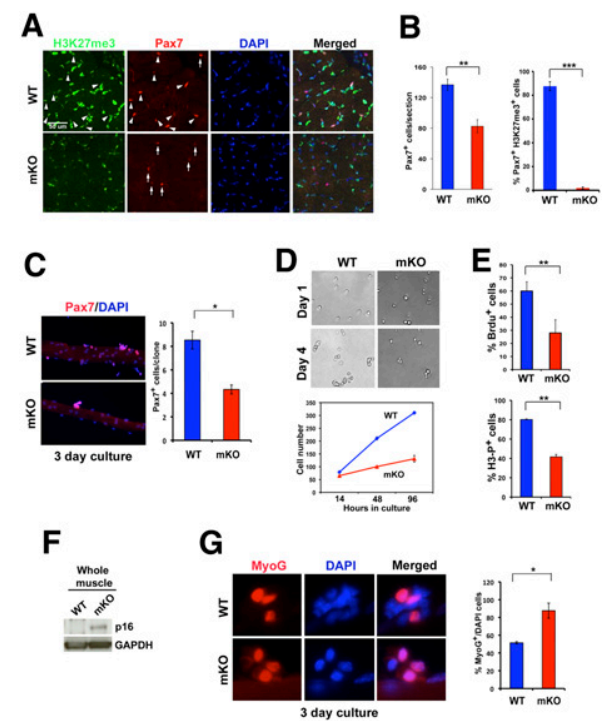

Figure 3. Skeletal muscle progenitors derived from Ezh $2^{\mathrm{mKO}}$ animals have proliferative defects and precociously activate myogenin. $(A, B)$ Immunostaining of H3K27me3 and Pax7 of P8 EDL. Arrowheads indicate cells stained positive for both Pax7 and H3K27me3. Arrows indicate $\mathrm{Pax} 7^{+} / \mathrm{H} 3 \mathrm{~K} 27 \mathrm{me} 3^{-}$cells. Data are presented as mean \pm SD $(n=3) ;\left(^{\star \star \star}\right) P<0.0005 ;\left(^{\star \star}\right) P<0.005$. (C) Pax7 immunostaining of EDL single myofibers isolated from wild-type (WT) and Ezh2 ${ }^{\mathrm{mK}}$ mice cultured for $3 \mathrm{~d} .\left(^{*}\right) P<0.05$. (D) FACS-isolated wild-type and Ezh2 ${ }^{\mathrm{mKO}} \mathrm{SCs}$ after 1 or $4 \mathrm{~d}$ in culture. Cells $\left(1.5 \times 10^{4}\right)$ of wild-type and Ezh2 ${ }^{\mathrm{mKO}}$ SCs were seeded, and the total number obtained from counting cells present in 10 independent microscopic fields after 14, 48 , and $96 \mathrm{~h}$ in culture was plotted in the curve graph $(n=4 ; P<$ 0.001 and $P<0.003$ for $42-\mathrm{h}$ and $96-\mathrm{h}$ counts, respectively). (E) Percentage of FACS-isolated wild-type and Ezh2 ${ }^{\text {mKO }}$ SCs that have incorporated BrdU or that stained positive for histone-H3 (H3-P). Data are presented as mean $\pm \mathrm{SD}$ for $\operatorname{BrdU}\left(n=3 ;\left[^{\star \star}\right] P<0.005\right)$ and H3-P $\left.\left(n=4 ;{ }^{\star \star}\right] P<0.005\right) .(F)$ Increased p16 protein in Ezh2 ${ }^{\text {mKO }}$ muscles. GAPDH serves as a loading control. (G) Myogenin immunostaining of SC clones from wild-type and Ezh2 ${ }^{\mathrm{mKO}}$ myofibers. Data are presented as mean $\pm \mathrm{SD}_{;}\left(^{\star}\right) P<0.05$.

tiation potential (Juan et al. 2009). Overall, these results indicate that EZH2 plays an important role in the SC's proliferation and differentiation.

\section{Muscle regeneration is compromised in Ezh2 ${ }^{m K O}$ animals}

The proliferative defects of SCs and the depletion of the quiescent SC pool observed in Ezh2 ${ }^{\mathrm{mKO}}$ mice suggested that muscle regeneration may be compromised in these animals. To test this hypothesis, muscle damage was induced by injecting the tibialis anterior (TA) muscle of adult (P60) wild-type and Ezh2 ${ }^{\mathrm{mKO}}$ animals with cardiotoxin (CTX). Three days after CTX injection, Pax7 and myogenin, which are normally undetectable by immunoblot in uninjured adult muscles (Fig. 1A), were readily seen in wild type but were reduced in Ezh2 $2^{\mathrm{mKO}}$ animals (Fig. 4A). Reduced myogenin expression in Ezh2 ${ }^{\mathrm{mKO}}$ animals is likely the consequence of defective SC proliferation rather than impaired differentiation, as Ezh2 ${ }^{\mathrm{mKO}} \mathrm{SCs}$ display anticipated myogenin expression (Fig. 3G). Seven days after CTX injection, proliferation of Pax $7^{+}$cells in the $E z h 2^{\mathrm{mKO}}$ regenerating muscle was severely impaired, as indicated by an almost 10 -fold reduction of doublepositive $\mathrm{Pax}^{+} /$phospho-H3 ${ }^{+}$cells (Fig. 4B). At this stage, 
Juan et al.

A
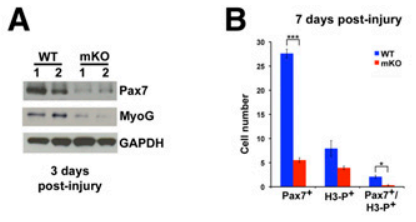

C
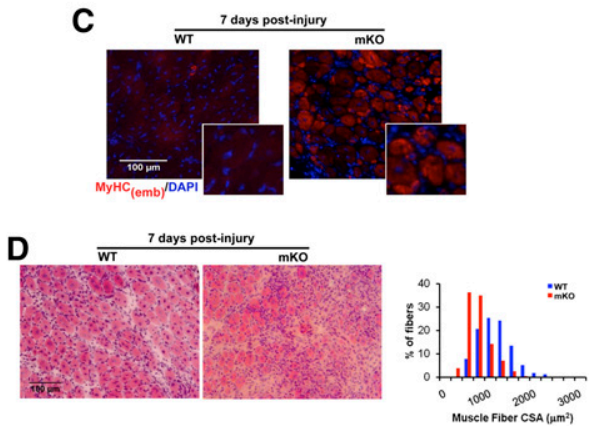

Figure 4. Impaired muscle regeneration in $E z h 2^{\mathrm{mKO}}$ animals. $(A)$ Immunoblots of limb muscle extracts from wild-type (WT) or Ezh2 ${ }^{\mathrm{mKO}}$ animals $(n=2) 3 \mathrm{~d}$ after CTX, probed with myogenin, Pax7, and GAPDH antibodies. (B) Pax7 and H3-P immunostaining of TA muscles from wild-type and Ezh2 $2^{\mathrm{mKO}}$ animals $7 \mathrm{~d}$ after CTX injection. Data are presented as mean $\pm \mathrm{SD}(n=3) ;\left(^{* \star *}\right) P<0.0005$; $\left({ }^{*}\right) P<0.05$. $(C)$ Embryonic MyHC $\left[\mathrm{MyHC}_{(\mathrm{emb})}\right]$ immunostaining in wild-type and $E z h 2^{\mathrm{mKO}}$ mice in 7-d regenerating myofibers. $(D) \mathrm{H} \& \mathrm{E}$ staining of transverse sections of wild-type or $E z h 2^{\mathrm{mKO}}$ regenerating TA muscles $7 \mathrm{~d}$ after CTX injection indicates that the CSA of centrally nucleated myofibers is reduced in Ezh2 ${ }^{\mathrm{mKO}}$ animals $(n=3)$. (Right panel) Ninety-five percent confidence intervals do not overlap.

while regenerating myofibers of littermate controls had almost extinguished expression of embryonic myosin heavy chain (eMyHC), a marker of muscle regeneration, Ezh $2^{\mathrm{mKO}}$ myofibers exhibited intense eMyHC staining and were smaller, indicating that muscle repair in Ezh2 ${ }^{\mathrm{mKO}}$ lagged behind that of control mice (Fig. 4C). Indeed, the majority of newly formed myofibers, identified by the presence of nuclei located in a central position, had a smaller CSA in Ezh2 ${ }^{\mathrm{mKO}}$ animals (Fig. 4D). Overall, these findings indicate that $\mathrm{EZH} 2$ is required for appropriate SC proliferation during muscle regeneration.

\section{Ezh2 maintains the transcriptional identity of SCs}

We compared transcriptional profiles of wild-type and Ezh2 ${ }^{\mathrm{mKO}}$ muscles by microarray analysis (Fig. 5A; Supplemental Table S1). Among the down-regulated transcripts in Ezh2 $2^{\mathrm{mKO}}$ muscle were several corresponding to developmental regulators and structural proteins (Supplemental Table S1). It is likely that reduced transcription is an indirect effect of Ezh2 ablation mediated by intermediate regulators, as $\mathrm{H} 3 \mathrm{~K} 27 \mathrm{me} 3$ is not known to be directly associated with transcriptional activation. Gene ontology (GO) analysis for up-regulated genes found significant enrichment for functional classes, including those corresponding to muscle functions (Supplemental Table S2). Indeed, transcripts for muscle-expressed titin, sarcolipin, myosin Myh7, myomesin3, cardiac actin, Ankrd1, and troponin Tnnil were increased in Ezh2 ${ }^{\mathrm{mKO}}$ (Fig. 5A; Supplemental Table S1). In addition, several developmental regulators expressed in multiple lineages that are PRC targets in ES cells were also upregulated (Fig. 5A; Supplemental Table S1). Among those were ZIC-1 (expressed in early somites and the cerebel- lum), Isl1 (expressed in cardiac progenitors and the pancreas), and Tbx1 (expressed in cardiac progenitors). Transcripts of structural genes expressed in other cell lineages were also up-regulated in Ezh2 ${ }^{\mathrm{mKO}}$. For instance, expression of the agouti-related protein homolog 1 (Agrp1), expressed in neurons of the arcuate nucleus of the hypothalamus (Hahn et al. 1998); the collagen Col22a1, specifically expressed in chondrocytes (Koch et al. 2004); and opsin1 (Opn1), encoding a retinal photopigment expressed in retinal cones (Shichida and Matsuyama 2009) was increased (Fig. 5A; Supplemental Table S1). Expression of some of the transcripts identified as upregulated by microarray analysis was evaluated independently by quantitative PCR (qPCR) and confirmed to be increased in the limb muscles of Ezh2 ${ }^{\mathrm{mKO}}$ animals. (Fig. $5 \mathrm{~B}, \mathrm{C})$. Importantly, expression of mixed cell lineage genes and p16 was increased in FACS-isolated quiescent Ezh2 ${ }^{\text {mKO }}$ SCs (Fig. 5E). However, muscle-specific transcripts increased in Ezh2 ${ }^{\mathrm{mKO}}$ muscles were not augmented in Ezh2 ${ }^{\mathrm{mKO}}$ SCs (data not shown), suggesting that their misregulation occurs in myofibers.

\section{PollI recruitment to mixed cell lineage genes and the Ink4a/Arf locus in Ezh2 ${ }^{\text {mKO }}$ SCs}

To mechanistically investigate how Ezh2 ablation causes gene derepression, we conducted chromatin immunoprecipitation (ChIP) assays with antibodies against

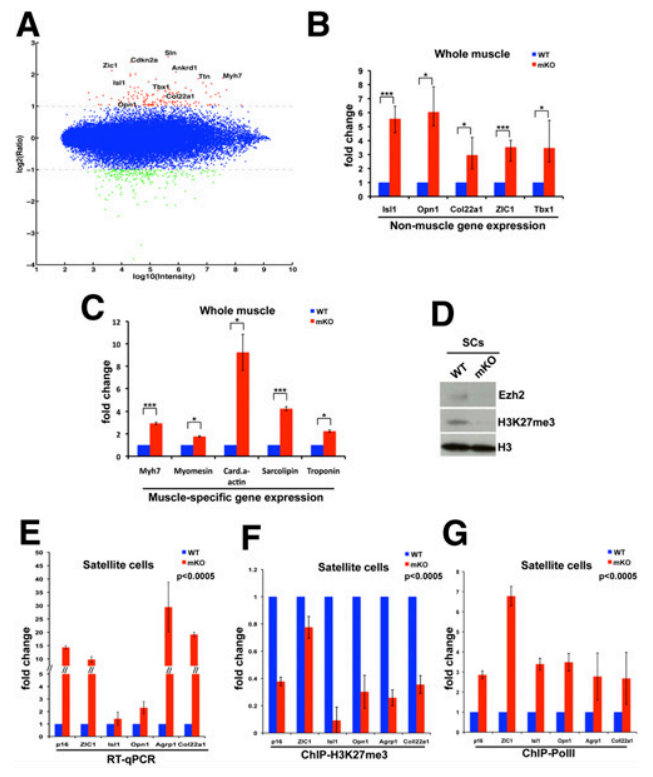

Figure 5. Ezh2 maintains transcriptional identity of SCs. (A) Log intensity versus ratio scatter plot of gene expression obtained from microarray data derived from muscles of wild-type $(n=2)$ and $E z h 2^{\mathrm{mKO}}$ $(n=2)$ animals. The $X$-axes represents the $\log _{10}$ of the average intensity of the data, and the $Y$-axes represents the $\log _{2}$ of their ratio. Each dot represents one gene. Up-regulated and down-regulated genes are colorcoded red and green, respectively (fold change $>2)$. $(B, C)$ Expression of selected up-regulated genes identified in $A$ by qPCR in muscles of wild-type or Ezh2 ${ }^{\mathrm{mKO}}$ animals. Data are presented as mean $\pm \mathrm{SD}(n=$ $3)_{;}\left(^{\star \star \star}\right) P<0.0005$; $\left(^{\star}\right) P<0.05$. $(D)$ EZH2 and H3K27me3 immunoblots of FACS-isolated Ezh2 ${ }^{\mathrm{mKO}}$ SCs. Total histone $\mathrm{H} 3$ serves as loading control. $(E)$ qPCR on selected up-regulated genes from FACSisolated wild-type or Ezh2 ${ }^{\mathrm{mKO}}$ SCs. Data are presented as mean \pm SD $(n=3) ; P<0.0005$ for all the values. $(F, G)$ ChIP-qPCR for H3K27me3 and PolII at selected genes up-regulated in Ezh2 ${ }^{\mathrm{mKO}}$ SCs. Data are presented as mean $\pm \mathrm{SD}(n=3) ; P<0.0005$ for all the values. 
H3K27me3 and PolII. ZIC-1, Ink4a/Arf (p16), Isl1, Opn1, and Coll22al genes were marked by H3K27me3, and PolII was undetectable in wild-type SCs. In contrast, H3K27me3 was significantly reduced and PolII was recruited at these genes in Ezh2 ${ }^{\mathrm{mKO}}$ SCs (Fig. 5D,F, G; Supplemental Fig. S4C). Overall, these results indicate that SCs are the source of mixed cell lineage and p16 gene misexpression, and that reduced H3K27me3 in Ezh2 ${ }^{\mathrm{mKO}}$ SCs allows PolII chromatin access, resulting in unwarranted gene transcription.

\section{Conditional ablation of Ezh2 in MyoD-expressing cells recapitulates the muscle phenotypes observed in Ezh2 ${ }^{m K O}$ mice}

Pax7 expression is not limited to SCs but extends to cells located in the CNS and craniofacial tissues (Jostes et al. 1990). Indeed, some Pax7-Cre- Ezh2 ${ }^{\mathrm{mKO}}$ mice with CNS defects were retrieved at E15.5 and E17.5 (data not shown). To ablate Ezh2 in committed skeletal myogenic cells $\left(\mathrm{MyoD}^{+}\right.$cells), we bred MyoD-Cre (Chen et al. 2005) and floxed Ezh2 mice (Supplemental Fig. S5A). Body and muscle mass were greatly reduced in $M y o D$-Cre-Ezh2 ${ }^{\mathrm{mKO}}$ mice (Supplemental Fig. S5B-E). Moreover, the number of Pax $7^{+}$cells was also reduced in muscle cross-sections (Supplemental Fig. S5F). Recent studies have documented an activation of the MyoD locus in prenatal SCs (Kanisicak et al. 2009). Thus, $M y o D$-Cre-Ezh2 ${ }^{\mathrm{mKO}}$ mice may have deleted the $E z h 2^{\mathrm{fl} / \mathrm{fl}}$ alleles in SCs capable of self-renewal. While p16 derepression in MyoD-Cre-Ezh2 ${ }^{\mathrm{mKO}}$ was comparable with that observed in Pax7-Cre-Ezh2 $2^{\mathrm{mKO}}$ mice, expression of mixed-lineage genes ZIC-1, Agrp1, and Coll22al was much less pronounced (Supplemental Fig. S5G). Overall, the phenotypic similarities of Pax7Cre-Ezh2 $2^{\mathrm{mKO}}$ and $M y o D$-Cre-Ezh2 $2^{\mathrm{mKO}}$ mice suggest that the observed muscle defects can be imputed to Ezh2 ablation in skeletal myogenic cells.

\section{Conclusions}

The present study revealed that EZH2 influences several aspects of SC biology, including self-renewal, proliferation, and cell identity.

Unlike other studies in which Ezh2 deletion was conditionally obtained in committed progenitors or differentiated cells (Chen et al. 2009; Ezhkova et al. 2009; Hirabayashi et al. 2009), we observed that Pax7-induced Ezh2 deletion resulted in derepression of developmental regulators and structural genes physiologically not expressed in SCs. We speculate that, in committed or differentiated cells, the chromatin structure at selected genomic regions may be insensitive to epigenetic modifications caused by Ezh2 ablation. Indeed, when Ezh2 was deleted in committed myogenic precursors $\left(\mathrm{MyoD}^{+}\right)$, gene misexpression was barely observed (Supplemental Fig. S5G). A more naive and plastic chromatin environment, such as that of ES cells or noncommitted $\mathrm{Pax}^{+} / \mathrm{Myf}^{-}$ stem cells, may react to PcG gene ablation by dysregulating gene expression (Boyer et al. 2006; Lee et al. 2006). In contrast to mixed-lineage genes, the Ink4a/Arf locus is derepressed in committed and differentiated Ezh2ablated cells (MyoD-Cre-Ezh2 ${ }^{\mathrm{mKO}}$ ) (Chen et al. 2009; Ezhkova et al. 2009; Hirabayashi et al. 2009; this study). Thus, different genomic chromatin structures may be susceptible to PcG regulation only at defined developmental windows. Interestingly, derepression of some of the mixed-lineage genes reported here has been observed in the skin of Ezh1/Ezh2 double-knockout mice (Ezhkova et al. 2011).

EZH2 has been reported to repress Pax7 expression (Palacios et al. 2010). Specifically, EZH2 knockdown in cultured SCs results in Pax7 activation only if induced when the Pax7 level starts declining (Palacios et al. 2010). Since Cre expression in Pax7-Cre mice is coincident with Pax7 transcription (Keller et al. 2004), it is likely that Ezh2 ablation in Ezh2 ${ }^{\text {mKO }}$ mice occurred at the onset of Pax7 expression. In addition to the different temporal Ezh2 inactivation strategies, cultured SCs may not experience the same physiological regulation attained in the animal, and may thus explain the different experimental outcomes.

In conclusion, the processes regulated by EZH2 are pivotal for SC homeostasis. As SCs hold therapeutic potential to treat muscle-wasting diseases (Kuang et al. 2008), PRC2 may be exploited as a target to promote ex vivo expansion and in vivo SC self-renewal.

\section{Materials and methods}

\section{Mice and animal care}

Mice were housed in a pathogen-free facility, and all experiments were performed according to the National Institutes of Health's (NIH) Animal Care and Use regulations. For a detailed animal description, see the Supplemental Material.

\section{Myotoxic injury}

The right TA muscle of 8 -wk-old wild-type and Ezh2 ${ }^{\mathrm{mKO}}$ mice was surgically exposed and injected to holding capacity $(\sim 50 \mu \mathrm{L})$ with 10 $\mu \mathrm{M}$ CTX, as described previously (Schertzer et al. 2007). The left TA muscle was not injected and served as an uninjured control.

\section{Histology}

For a detailed histology protocol, see the Supplemental Material.

FACS sorting, myofiber isolation, BrdU labeling, immunofluorescence, and image acquisition

SC FACS sorting was performed as described previously (Joe et al. 2010). $\mathrm{BrdU}$ staining and immunofluorescence protocols are described in the Supplemental Material.

\section{Transferase dUTP nick end-labeling (TUNEL) assay}

FACS-sorted SCs were examined by terminal deoxynucleotidyl TUNEL assay (Roche Applied Science) according to the manufacturer's instructions.

\section{Gene expression analyses}

Total RNA from either whole-muscle or FACS-isolated SCs was reversetranscribed using a cDNA synthesis kit (Applied Biosystems) and subjected to qPCR analysis. Gene expression analyses are detailed in the Supplemental Material.

\section{Immunoblots}

Muscles or FACS-isolated SCs were lysed, and their extracts were resolved by SDS-PAGE and transferred onto nitrocellulose filters. Specific antibodies used to perform immunoblots are described in Supplemental Table 4.

\section{ChIP assay}

Cross-linking and ChIP were performed as described (Caretti et al. 2004) with minor modifications (see the Supplemental Material). 


\section{Acknowledgments}

We thank Mario Capecchi, David Goldhamer, and Alexander Tarakhovsky for sharing the Pax7-Cre, MyoD-Cre, and Ezh2 $2^{\mathrm{fl} / \mathrm{fl}}$ animals, respectively. Fabio Rossi provided advice with the FACS experiments, Jeffrey Lay helped with cell sorting, and Gustavo Gutierrez-Cruz assisted with animal genotyping. Members of the NIAMS Laboratory Animal Care and Use Section and NIAMS Light Imaging Section are kindly acknowledged. J.G.R. was supported by an Overseas Biomedical Research Fellowship from the $\mathrm{NH}$ and MRC (Australia). This work was supported in part by the Intramural Research Program of the National Institute of Arthritis, Musculoskeletal, and Skin Diseases of the National Institutes of Health.

\section{References}

Boyer LA, Plath K, Zeitlinger J, Brambrink T, Medeiros LA, Lee TI, Levine SS, Wernig M, Tajonar A, Ray MK, et al. 2006. Polycomb complexes repress developmental regulators in murine embryonic stem cells. Nature 441: 349-353.

Bracken AP, Kleine-Kohlbrecher D, Dietrich N, Pasini D, Gargiulo G, Beekman C, Theilgaard-Monch K, Minucci S, Porse BT, Marine JC, et al. 2007. The Polycomb group proteins bind throughout the INK4A-ARF locus and are disassociated in senescent cells. Genes Dev 21: 525-530.

Buckingham M, Relaix F. 2007. The role of Pax genes in the development of tissues and organs: Pax3 and Pax7 regulate muscle progenitor cell functions. Annu Rev Cell Dev Biol 23: 645-673.

Caretti G, Di Padova M, Micales B, Lyons GE, Sartorelli V. 2004. The Polycomb Ezh2 methyltransferase regulates muscle gene expression and skeletal muscle differentiation. Genes Dev 18: 2627-2638.

Chamberlain SJ, Yee D, Magnuson T. 2008. Polycomb repressive complex 2 is dispensable for maintenance of embryonic stem cell pluripotency. Stem Cells 26: 1496-1505.

Chen JC, Mortimer J, Marley J, Goldhamer DJ. 2005. MyoD-cre transgenic mice: a model for conditional mutagenesis and lineage tracing of skeletal muscle. Genesis 41: 116-121.

Chen H, Gu X, Su IH, Bottino R, Contreras JL, Tarakhovsky A, Kim SK. 2009. Polycomb protein Ezh2 regulates pancreatic $\beta$-cell Ink4a/Arf expression and regeneration in diabetes mellitus. Genes Dev 23: 975-985.

Collins CA, Olsen I, Zammit PS, Heslop L, Petrie A, Partridge TA, Morgan JE. 2005. Stem cell function, self-renewal, and behavioral heterogeneity of cells from the adult muscle satellite cell niche. Cell 122: 289-301.

Conboy MJ, Karasov AO, Rando TA. 2007. High incidence of non-random template strand segregation and asymmetric fate determination in dividing stem cells and their progeny. PLoS Biol 5: e102. doi: 10.1371/ journal.pbio.0050102.

Ezhkova E, Pasolli HA, Parker JS, Stokes N, Su IH, Hannon G, Tarakhovsky A, Fuchs E. 2009. Ezh2 orchestrates gene expression for the stepwise differentiation of tissue-specific stem cells. Cell 136: 1122-1135.

Ezhkova E, Lien WH, Stokes N, Pasolli HA, Silva JM, Fuchs E. 2011. EZH1 and EZH2 cogovern histone H3K27 trimethylation and are essential for hair follicle homeostasis and wound repair. Genes Dev 25: 485-498.

Hahn TM, Breininger JF, Baskin DG, Schwartz MW. 1998. Coexpression of Agrp and NPY in fasting-activated hypothalamic neurons. Nat Neurosci 1: 271-272.

Hirabayashi Y, Suzki N, Tsuboi M, Endo TA, Toyoda T, Shinga J, Koseki H, Vidal M, Gotoh Y. 2009. Polycomb limits the neurogenic competence of neural precursor cells to promote astrogenic fate transition. Neuron 63: 600-613.

Joe AW, Yi L, Natarajan A, Le Grand F, So L, Wang J, Rudnicki MA, Rossi FM. 2010. Muscle injury activates resident fibro/adipogenic progenitors that facilitate myogenesis. Nat Cell Biol 12: 153-163.

Jostes B, Walther C, Gruss P. 1990. The murine paired box gene, Pax7, is expressed specifically during the development of the nervous and muscular system. Mech Dev 33: 27-37.

Juan AH, Kumar RM, Marx JG, Young RA, Sartorelli V. 2009. mir-214dependent regulation of the Polycomb protein Ezh2 in skeletal muscle and embryonic stem cells. Mol Cell 36: 61-74.

Kanisicak O, Mendez JJ, Yamamoto S, Yamamoto M, Goldhamer DJ. 2009. Progenitors of skeletal muscle satellite cells express the muscle determination gene, MyoD. Dev Biol 332: 131-141.

Keller C, Hansen MS, Coffin CM, Capecchi MR. 2004. Pax3:Fkhr interferes with embryonic Pax3 and Pax7 function: implications for alveolar rhabdomyosarcoma cell of origin. Genes Dev 18: 26082613.

Koch M, Schulze J, Hansen U, Ashwodt T, Keene DR, Brunken WJ, Burgeson RE, Bruckner P, Bruckner-Tuderman L. 2004. A novel marker of tissue junctions, collagen XXII. J Biol Chem 279: 22514-22521.

Kotake Y, Cao R, Viatour P, Sage J, Zhang Y, Xiong Y. 2007. pRB family proteins are required for $\mathrm{H} 3 \mathrm{~K} 27$ trimethylation and Polycomb repression complexes binding to and silencing p16INK $4 \alpha$ tumor suppressor gene. Genes Dev 21: 49-54.

Kuang S, Kuroda K, Le Grand F, Rudnicki MA. 2007. Asymmetric selfrenewal and commitment of satellite stem cells in muscle. Cell 129: 999-1010.

Kuang S, Gillespie MA, Rudnicki MA. 2008. Niche regulation of muscle satellite cell self-renewal and differentiation. Cell Stem Cell 2: 22-31.

Lee TI, Jenner RG, Boyer LA, Guenther MG, Levine SS, Kumar RM, Chevalier B, Johnstone SE, Cole MF, Isono K, et al. 2006. Control of developmental regulators by Polycomb in human embryonic stem cells. Cell 125: 301-313.

Montarras D, Morgan J, Collins C, Relaix F, Zaffran S, Cumano A, Partridge T, Buckingham M. 2005. Direct isolation of satellite cells for skeletal muscle regeneration. Science 309: 2064-2067.

Palacios D, Mozzetta C, Consalvi S, Caretti G, Saccone V, Proserpio V, Marquez VE, Valente S, Mai A, Forcales SV, et al. 2010. TNF/p38 $\alpha$ / Polycomb signaling to Pax 7 locus in satellite cells links inflammation to the epigenetic control of muscle regeneration. Cell Stem Cell 7: 455-469.

Pasini D, Bracken AP, Hansen JB, Capillo M, Helin K. 2007. The polycomb group protein Suz12 is required for embryonic stem cell differentiation. Mol Cell Biol 27: 3769-3779.

Pereira JD, Sansom SN, Smith J, Dobenecker MW, Tarakhovsky A, Livesey FJ. 2010. Ezh2, the histone methyltransferase of PRC2, regulates the balance between self-renewal and differentiation in the cerebral cortex. Proc Natl Acad Sci 107: 15957-15962.

Sauvageau M, Sauvageau G. 2010. Polycomb group proteins: multifaceted regulators of somatic stem cells and cancer. Cell Stem Cell 7: 299-313.

Schertzer JD, Gehrig SM, Ryall JG, Lynch GS. 2007. Modulation of insulin-like growth factor (IGF)-I and IGF-binding protein interactions enhances skeletal muscle regeneration and ameliorates the dystrophic pathology in mdx mice. Am I Pathol 171: 1180-1188.

Shea KL, Xiang W, LaPorta VS, Licht JD, Keller C, Basson MA, Brack AS. 2010. Sproutyl regulates reversible quiescence of a self-renewing adult muscle stem cell pool during regeneration. Cell Stem Cell 6: 117-129.

Shen X, Liu Y, Hsu YJ, Fujiwara Y, Kim J, Mao X, Yuan GC, Orkin SH. 2008. EZH1 mediates methylation on histone H3 lysine 27 and complements EZH2 in maintaining stem cell identity and executing pluripotency. Mol Cell 32: 491-502.

Sherwood RI, Christensen JL, Conboy IM, Conboy MJ, Rando TA, Weissman IL, Wagers AJ. 2004. Isolation of adult mouse myogenic progenitors: functional heterogeneity of cells within and engrafting skeletal muscle. Cell 119: 543-554.

Shichida Y, Matsuyama T. 2009. Evolution of opsins and phototransduction. Philos Trans R Soc Lond B Biol Sci 364: 2881-2895.

Shinin V, Gayraud-Morel B, Gomes D, Tajbakhsh S. 2006. Asymmetric division and cosegregation of template DNA strands in adult muscle satellite cells. Nat Cell Biol 8: 677-687.

Su IH, Basavaraj A, Krutchinsky AN, Hobert O, Ullrich A, Chait BT, Tarakhovsky A. 2003. Ezh2 controls B cell development through histone H3 methylation and Igh rearrangement. Nat Immunol 4: 124131. 


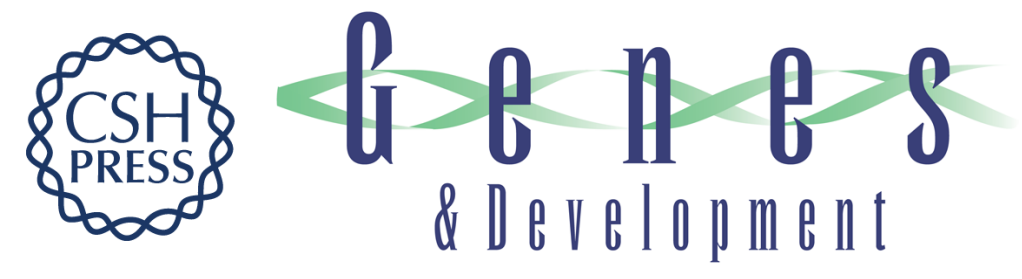

\section{Polycomb EZH2 controls self-renewal and safeguards the transcriptional identity of skeletal muscle stem cells}

Aster H. Juan, Assia Derfoul, Xuesong Feng, et al.

Genes Dev. 2011, 25:

Access the most recent version at doi:10.1101/gad.2027911

\section{Supplemental http://genesdev.cshlp.org/content/suppl/2011/04/12/25.8.789.DC1 \\ Material}

Related Content

Polycomb-mediated repression during terminal differentiation: what don't you want to be when you grow up?

Melissa L. Conerly, Kyle L. MacQuarrie, Abraham P. Fong, et al.

Genes Dev. May , 2011 25: 997-1003

References

This article cites 35 articles, 10 of which can be accessed free at: http://genesdev.cshlp.org/content/25/8/789.full.html\#ref-list-1

Articles cited in:

http://genesdev.cshlp.org/content/25/8/789.full.html\#related-urls

\section{License}

Email Alerting

Service

Receive free email alerts when new articles cite this article - sign up in the box at the top right corner of the article or click here.

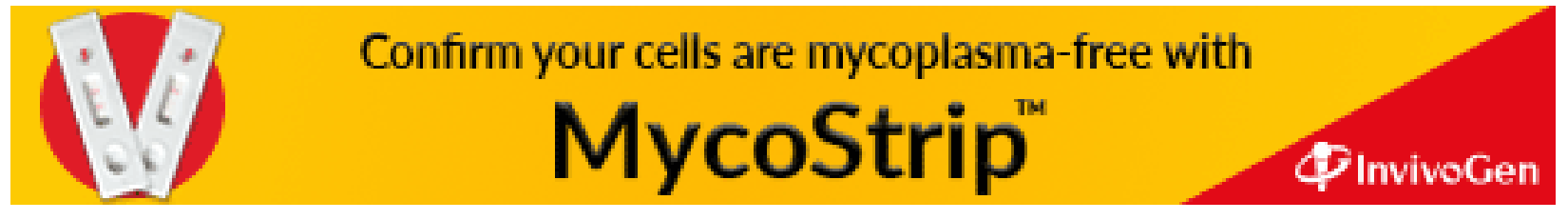

